\title{
COMPARING DIFFERENT NIRS DEVICES AND THEIR SENSORS FOR MONITORING REGIONAL CEREBRAL OXYGEN SATURATION IN NEONATES
}

\author{
L. Dix, P. Lemmers, F. van Bel \\ Neonatology, Wilhelmina Children's Hospital UMC, Utrecht, The Netherlands
}

Background and aim: Near-infrared spectroscopy (NIRS)-monitored regional cerebral oxygen saturation $\left(\mathrm{rScO}_{2}\right)$ in neonates has been increasingly used to assess cerebral oxygen delivery and extraction. Consequently neonatal sensors were designed with their own algoritms to separate the signals of oxy- and deoxyhemoglobin. However,published reference values are mostly based on studies using adult (conventional) sensors with different algoritms.

To compare $\mathrm{rScO}_{2}$ values between the conventional NIRS-sensors of 3 different brands and those especially designed for use on the neonatal head.

Methods: 56 neonates admitted to our NICU were included. $\mathrm{rScO}_{2}$ 's were measured left and right frontoparietally with a conventional and neonatal sensor on each side for at least one hour.

Then the sensors were switched to the opposite side and measurements were continued for at least another hour.

Results: We found a significant correlation between conventional and neonatal sensors $(\mathrm{p}<0.01-\mathrm{p}<0.001)$. However, Bland-Altman analysis showed a consistent difference between sensors from 8 -to- $13 \%$, showing higher values obtained with the neonatal sensors.

Conclusions: Although a good correlation between conventional and neonatal NIRS sensors was detected, reference values should be re-established when using newly designed neonatal sensors.

Moreover $\mathrm{rScO}_{2}$ values in the higher range measured with neonatal sensors appeared to be less reliable which may be a problem in case of hyperoxia, which is in particular a problem in the extremely preterm neonate whose brain is prone for hyperoxic-induced brain damage. 